\title{
Non-viral FoxM1 gene delivery to hepatocytes enhances liver repopulation
}

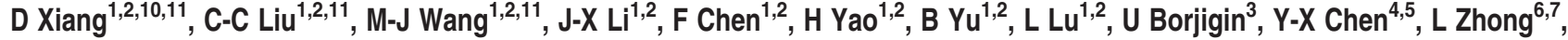 \\ KJ Wangensteen ${ }^{8}$, Z-Y He ${ }^{*, 1,2}, X_{\text {Wang }}{ }^{\star, 3,4,9}$ and Y-P Hu$u^{\star, 1,2}$
}

Hepatocyte transplantation as a substitute strategy of orthotopic liver transplantation is being studied for treating end-stage liver diseases. Several technical hurdles must be overcome in order to achieve the therapeutic liver repopulation, such as the problem of insufficient expansion of the transplanted hepatocytes in recipient livers. In this study, we analyzed the application of FoxM1, a cell-cycle regulator, to enhance the proliferation capacity of hepatocytes. The non-viral sleeping beauty (SB) transposon vector carrying FoxM1 gene was constructed for delivering FoxM1 into the hepatocytes. The proliferation capacities of hepatocytes with FoxM1 expression were examined both in vivo and in vitro. Results indicated that the hepatocytes with FoxM1 expression had a higher proliferation rate than wild-type (WT) hepatocytes in vitro. In comparison with WT hepatocytes, the hepatocytes with FoxM1 expression had an enhanced level of liver repopulation in the recipient livers at both sub-acute injury (fumaryl acetoacetate hydrolase (Fah) $)^{-/}$mice model) and acute injury (2/3 partial hepatectomy mice model). Importantly, there was no increased risk of tumorigenicity with FoxM1 expression in recipients even after serial transplantation. In conclusion, expression of FoxM1 in hepatocytes enhanced the capacity of liver repopulation without inducing tumorigenesis. FoxM1 gene delivered by non-viral SB vector into hepatocytes may be a viable approach to promote therapeutic repopulation after hepatocyte transplantation.

Cell Death and Disease (2014) 5, e1252; doi:10.1038/cddis.2014.230; published online 22 May 2014

Subject Category: Experimental Medicine

Hepatocyte transplantation has been studied for decades as a substitute way of therapy to orthotopic liver transplantation for treating end-stage liver diseases. ${ }^{1}$ Although transplanted hepatocytes have been shown to engraft in recipient livers, ${ }^{2}$ and repopulation of up to $\sim 2 \%$ of the liver has been reported, ${ }^{3}$ it is not yet clear whether there is any clinical benefit to transplantation. A method to expand transplanted hepatocytes inside receipt livers would render hepatocytes more suitable for liver repopulation. ${ }^{4}$ With a selective advantage over the host liver cells, the transplanted hepatocytes could efficiently expand to a level that may lead to a therapeutic benefit. Two strategies could be used to achieve selective advantage of transplanted hepatocytes. The first one is either to suppress host liver cell proliferation through blocking their regenerative capacity by retrorsine ${ }^{5}$ or induce death in host cells, which happens in the uPA transgenic mouse ${ }^{6}$ or fumaryl acetoacetate hydrolase (Fah) knockout mouse (Fah $^{-1-}$ mice). ${ }^{1}$ However, this strategy is hard to apply in clinical situations. The second one is to selectively enhance the growth and survival of transplanted hepatocytes by activating pathways that regulate the cell cycle to generate 'superhepatocytes' with augmented proliferation capacity. With an enhanced capacity of proliferation, hepatocytes from knockout mice of cell cycle inhibitor p27 resulted in an improved efficiency of liver repopulation in livers of recipient mice. ${ }^{7}$ This finding proved that the principle of manipulating pathways of cell cycle could be used for promoting the liver repopulation of transplanted hepatocytes. Expression of positive regulators of the cell cycle could also be applied for the purpose of promoting the liver repopulation of transplanted hepatocyte.

Forkhead box M1 (FoxM1) protein has been considered as one candidate for promoting expansion of donor hepatocytes in order to reach therapeutic liver repopulation. ${ }^{8}$ Known as a key cell-cycle regulator of both G1/S phase transition and G2/M transition, ${ }^{9}$ FoxM1 is highly expressed in most embryonic tissues. FoxM1 is necessary for hepatoblast mitosis and development of intrahepatic bile ducts and vessels during liver morphogenesis. ${ }^{10}$ Hepatocytes with sustained expression of

\footnotetext{
${ }^{1}$ Department of Cell Biology, Second Military Medical University, Shanghai, China; ${ }^{2}$ Center for Stem Cell and Medicine, The Graduate School, Second Military Medical University, Shanghai, China; ${ }^{3}$ The Key Laboratory of National Education Ministry for Mammalian Reproductive Biology and Biotechnology, Inner Mongolia University, Huhhot, China; ${ }^{4}$ Department of Laboratory Medicine and Pathology, University of Minnesota, Minneapolis, MN, USA; ${ }^{5}$ Department of Medicine, University of Minnesota, Minneapolis, MN, USA; ${ }^{6}$ School of Pharmaceutical Sciences, Sun Yat-Sen University, Guangzhou, China; ${ }^{7}$ Shenzhen Center for ADR Monitoring, Shenzhen, China; ${ }^{8}$ Division of Gastroenterology, Department of Medicine, University of Pennsylvania, Philadelphia, PA, USA and ${ }^{9}$ Hepatoscience Incorporation, Palo Alto, CA, USA ${ }^{*}$ Corresponding authors: Z-Y He or Y-P Hu, Department of Cell Biology, Second Military Medical University, 800 Xiangyin Road, Shanghai 200433, China. Tel: + 86218187 0946; Fax: + 86218187 0948; E-mail: zyhe@ @mmu.edu.cn (Z-YH) or Tel: + 86218187 0943; Fax: + 86218187 0948; E-mail: yphu@ @mmu.edu.cn (Y-PH) or X Wang, The Key Laboratory of National Education Ministry for Mammalian Reproductive Biology and Biotechnology, Inner Mongolia University, Huhhot 010021, China. Tel/Fax: + 8604714994 329; E-mail: wangxin_cn@imu.edu.cn

${ }^{10}$ Current address: Naval Medical Research Institute, Shanghai 200433, China

${ }^{11}$ These authors contributed equally to this work.

Keywords: FoxM1; sleeping beauty transposon; non-viral; hepatocyte transplantation; liver repopulation

Abbreviations: SB, sleeping beauty; FAH, fumaryl acetoacetate hydrolase; NTBC, 2-(2-nitro-4-trifluoromethylbenzoyl)-1,3-cyclohexanedione; IHC, immunohistochemistry Received 08.1.14; revised 03.4.14; accepted 14.4.14; Edited by M Agostini
} 
FoxM1 enter into $\mathrm{S}$ phase at least $8 \mathrm{~h}$ earlier than wild-type (WT) hepatocytes after partial hepatectomy. ${ }^{11}$ On the other hand, inactivation of FoxM1 in liver reduces the level of hepatocyte DNA replication and blocks mitosis during mouse liver regeneration. ${ }^{12}$ In livers of old mice, growth hormoneinduced FoxM1 expression restores normal levels of liver regeneration after partial hepatectomy. ${ }^{13}$ Similarly, FoxM1 expression through adenovirus-based gene delivery restores liver regeneration in old mice, which is mediated by both decreasing p27 activity and increasing activity of cell cycle agonists Cdc25B. ${ }^{14}$ These collective findings strongly support the potential application of FoxM1 to promote donor hepatocytes proliferation to compete with host hepatocytes during liver regeneration. A previous report indicated that hepatocytes of FoxM1 transgenic mouse had greater repopulation capacity than WT hepatocytes in host livers of UPA/SCID mice subjected to liver injury. ${ }^{15}$ This finding suggested there is an advantage to hepatocytes with sustained expression of FoxM1 for various situations in which repopulation occurs. With a proper method to deliver into donor hepatocytes, FoxM1 may be used to promote donor hepatocyte expansion after cell transplantation.

Here, we confirmed that transgenic hepatocytes with sustained FoxM1 expression have enhanced capacity for liver repopulation in the $\mathrm{Fah}^{-1}$ mice recipients with induced host hepatocyte death and also in the $\mathrm{Fah}^{-1-}$ mice recipients with normal healthy hepatocytes after partial hepatectomy. Sleeping beauty (SB) transposon vector has been regarded as one of most promising gene delivery system of gene therapy ${ }^{16}$ and has already been used in clinical trials. ${ }^{17}$ We constructed a SB transposon vector containing a FoxM1 gene to deliver it into hepatocytes before cell transplantation. The proliferation capacities of hepatocytes with FoxM1 expression were examined both in vivo and in vitro, in order to test possible applications of FoxM1 for future therapeutic purposes in liver repopulation.

\section{Results}

Hepatocytes with constitutive FoxM1 expression repopulated host livers more rapidly. Previous results have shown that $\mathrm{Fah}^{-1-}$ mice undergo repopulation with WT hepatocytes upon induction of hepatocyte injury by withdrawal of the drug NTBC (2-(2-nitro-4-trifluoromethylbenzoyl)-1,3-cyclohexanedione). ${ }^{18}$ We expected to get the similar results with hepatocytes from TTR-FoxM1 transgenic mice, as previous results showed a significantly higher efficiency of liver repopulation than WT hepatocytes in the uPA mouse model of liver injury. ${ }^{15}$

We isolated donor hepatocytes with sustained expression of human FoxM1 under the control of liver specific transthyretin (TTR) promoter from TTR-FoxM1 transgenic mice ${ }^{11}$ to examine whether FoxM1 enhances liver repopulation in $\mathrm{Fah}^{-1-}$ mice. As donor hepatocytes had a strain background that is different than $\mathrm{Fah}^{-1-}$ mice, we used immunodeficient $\mathrm{Fah}^{-1-} \mathrm{Rag}^{-2^{-1-}}$ mice as hosts to avoid immune rejection. ${ }^{19}$ In all, $2 \times 10^{5}$ TTR-FoxM1 hepatocytes were injected into the spleen of hosts. The same amount of $\beta$-gal ${ }^{+}$hepatocytes from Rosa26-LacZ mice were used as a control for hepatocytes without ectopic FoxM1 expression.
The level of liver repopulation was determined at 2, 4, 6 and 8 weeks after hepatocyte transplantation. Repopulation nodules from TTR-FoxM1 hepatocytes could be observed in the livers of $\mathrm{Fah}^{-1-} \mathrm{Rag}-2^{-1-}$ recipients (Figure 1a). In comparison with $\beta$-gal ${ }^{+}$hepatocytes, TTR-FoxM1 hepatocytes repopulated host liver to the higher levers at 2, 4 and 6 weeks after transplantation (Figures $1 \mathrm{~b}$ and $\mathrm{c}$ ). Although there is no significant difference in the levels of complete liver repopulation between two kinds of hepatocytes at 8 weeks after transplantation and afterward, the higher proliferation rate of FoxM1 ${ }^{+}$hepatocytes made it possible that TTRFoxM1 hepatocytes could complete liver repopulation 2 weeks ahead of the $\beta$-gal ${ }^{+}$hepatocytes.

Next, a method of competitive repopulation ${ }^{20}$ was used to compare the capacity for liver repopulation between TTRFoxM1 hepatocytes and $\beta$-gal ${ }^{+}$hepatocytes during liver repopulation. TTR-FoxM1 hepatocytes and $\beta$-gal ${ }^{+}$hepatocytes were mixed at a $1: 1$ ratio, and $2 \times 10^{5}$ mixed hepatocytes were transplanted into livers of $\mathrm{Fah}^{-/-} \mathrm{Rag}^{-2^{-1-}}$ mice. Southern blot analysis was previously used to quantitatively determine the contribution of each type of donor hepatocyte to liver repopulation. ${ }^{20}$ We applied this analysis for competitive repopulation in our study. At each time point during liver regeneration, TTR-FoxM1 hepatocytes contributed a greater amount of donor cell DNA than $\beta$-gal ${ }^{+}$hepatocytes (Figure $1 \mathrm{~d}$ ). At 8 weeks after completing liver repopulation, TTR-FoxM1 hepatocytes contributed $70 \% \pm 5 \%$, while $\beta$-gal ${ }^{+}$hepatocytes only contributed $22 \% \pm 8 \%$ (Figure $1 \mathrm{~d}$ ). Furthermore, a direct comparison between TTR-FoxM1 hepatocytes and $\beta$-gal ${ }^{+}$ hepatocytes was studied in WT recipient mice with partial hepatectomy $(\mathrm{PHx})$. In all, $2 \times 10^{5}$ equally mixed TTR-FoxM1 hepatocytes and $\beta$-gal ${ }^{+}$hepatocytes were transplanted into the livers of WT mice that were treated with standard 2/3 PHx. The result also showed an enhanced capacity for liver repopulation with TTR-FoxM1 hepatocytes. TTR-FoxM1 hepatocytes contributed $5-8 \%$ of total hepatocytes in regenerated livers after $\mathrm{PHx}$, while $\beta$-gal ${ }^{+}$hepatocytes were $<1 \%$ of the total (Figure 1e).

In summary, TTR-FoxM1 enhances hepatocyte proliferation compared with WT hepatocytes.

FoxM1 can be effectively delivered into hepatocytes in vivo. We have established a facile method for delivering multiple genes to somatic hepatocytes using SB transposon system, ${ }^{21,22}$ and have found that the SB transposon system is effective in delivering genes into hepatocytes. In the following experiments, pKT2/FAH-hFoxM1-SB was constructed in which a CMV enhancer/chicken $\beta$-actin promoter/ $\beta$-globin intron fusion sequence (Caggs) regulates expression of human FoxM1 gene, and SV40 promoter regulates expression of Fah gene from the same transcript. The Fah gene was delivered to correct metabolic deficiency in hepatocytes of $\mathrm{Fah}^{-1-}$ mice. In addition, a PGK promoter-driven SB transposase gene is outside of the transposon in the same plasmid. A vector with a reversed FoxM1 gene (pKT2/FAHrhFoxM1-SB) was used as control. A schematic summarizing of the plasmid construction is shown in Figure $2 \mathrm{a}$.

FoxM1 SB vectors were delivered into hepatocytes of $\mathrm{Fah}^{-1-}$ mice by hydrodynamic tail vein injection. Results of immunohistochemistry (IHC) in the same section indicated 

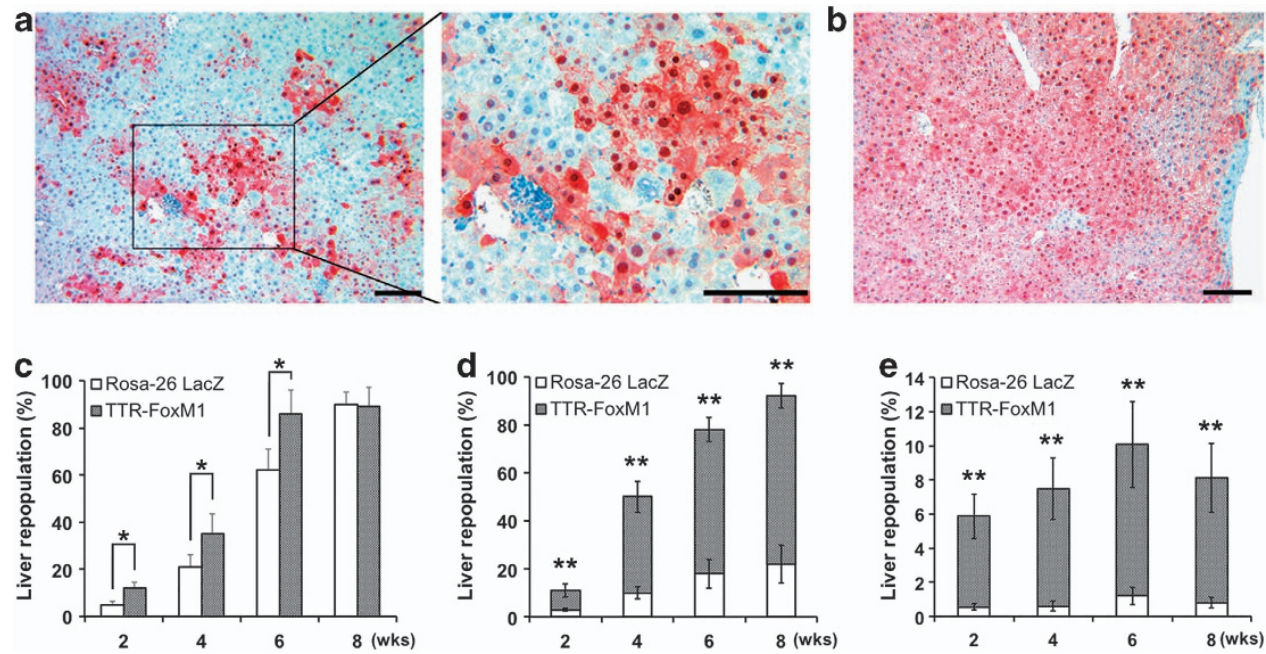

Figure 1 TTR-FoxM1 hepatocytes possess enhanced capacity of liver repopulation. (a) Liver repopulation at 4 weeks after transplantation and normal morphology of donor hepatocytes in recipient livers are shown by anti-FAH IHC staining. (b) Six weeks after transplantation, over $80 \%$ were repopulated by transplanted cells in recipient mice. Scar bar: $200 \mu \mathrm{m}$. (c) By examining the proportion of $\mathrm{FAH}^{+}$cells in recipient liver, levels of liver repopulation were detected at 2, 4, 6, 8 weeks after TTR-FoxM1 and Rosa26-LacZ hepatocytes transplanted into Fah ${ }^{-1}$ Rag-2 ${ }^{-1-}$ mice separately. (d and e) Equal number of TTR-FoxM1 hepatocytes and Rosa26-LacZ hepatocytes were mixed and separately transplanted into livers of Fah ${ }^{-1-}$ Rag-2 $2^{-1-}$ mice (d) and WT mice with PHx (e). Southern blot was used for quantitative analysis in order to detect each kind of donor hepatocytes in contribution of final liver repopulation at 2, 4, 6 and 8 weeks after transplantation. Data represented as mean \pm S.D. ${ }^{*} P<0.05,{ }^{*} P<0.01$

that $\mathrm{FAH}$ and FoxM1 double-positive $\left(\mathrm{FAH}^{+} \mathrm{FoxM}{ }^{+}\right)$hepatocyte nodules were found in the livers of mice that received pKT2/FAH-hFoxM1-SB plasmid injections (FoxM1 group) at 8 weeks after injection (Figure $2 \mathrm{~b}$, upper), while only $\mathrm{FAH}^{+}$ FoxM1 ${ }^{-}$hepatocytes were found in the control group (Figure 2b, lower). $\mathrm{FAH}^{+} \mathrm{FoxM}^{+}$hepatocytes were counted in the liver sections at several time points from 2 to 8 weeks. The proportions of $\mathrm{FAH}^{+}$cells and $\mathrm{FoxM1}^{+}$cells in all surveyed liver sections were highly correlated (Figure $2 \mathrm{c}$ ). These results suggested that all $\mathrm{FAH}^{+}$cells were also FoxM1 ${ }^{+}$cells. Therefore, the amount of FoxM1 ${ }^{+}$cells could be known from the counting of $\mathrm{FAH}^{+}$cells in liver sections. Although the variations existed in individual mouse and rate of FoxM1 gene transfection efficiency, the average repopulation rates for $\mathrm{FAH}^{+}$hepatocytes in FoxM1 group were higher than those for $\mathrm{FAH}^{+}$hepatocytes in control group (Figure 2d), our results confirmed that SB delivery system used in the study could be effectively applied in delivering FoxM1 gene into mature hepatocytes for promoting their cell proliferation capacity.

Enhanced cell expansion capacity of hepatocytes with FoxM1 expression. Previous studies have shown that transplantation of $\mathrm{FAH}^{+}$hepatocytes in $\mathrm{Fah}^{-1-}$ mice can reach $>90 \%$ repopulation of the liver of $\mathrm{Fah}^{-1-}$ mouse recipients. ${ }^{23}$ After FoxM1-SB plasmid injection, livers of primary recipients with high level of repopulation ( $>50 \%$ $\mathrm{FAH}^{+} \mathrm{FoxM}_{1}{ }^{+}$hepatocyte on sections) were perfused to isolate hepatocytes and perform serial transplantation. Complete liver repopulation was obtained from $\mathrm{FAH}^{+}$ FoxM1 ${ }^{+}$double-positive hepatocytes after two rounds of serial transplantation (data not shown). In order to determine whether there is enhanced liver repopulation in hepatocytes modified by FoxM1 SB vectors, $\mathrm{FAH}^{+}$FoxM1 ${ }^{+}$hepatocytes were isolated from $\mathrm{Fah}^{-1-}$ mice recipients with complete liver repopulation (>90\%). In all, $2 \times 10^{5} \mathrm{FAH}^{+} \mathrm{FoxM}{ }^{+}$ hepatocytes were transplanted into $\mathrm{Fah}^{-1-}$ mice, while the same amount $\left(2 \times 10^{5}\right)$ of WT hepatocytes were transplanted into $\mathrm{Fah}^{-1-}$ mice in a control group. At 2, 4, 6 and 8 weeks after transplantation, the efficiency of liver repopulation from $\mathrm{FAH}^{+} \mathrm{FoxM}^{+}{ }^{+}$hepatocytes was $14 \% \pm 1.71 \%$, $39 \% \pm 4.47 \%, 79 \% \pm 1.29 \%$ and $90 \% \pm 5.33 \%$, respectively, while the efficiency of liver repopulation from WT hepatocytes $\left(\mathrm{FAH}^{+} \mathrm{FoxM}^{-}\right)$was $5 \% \pm 1.52 \%, 21 \% \pm 5.15 \%$, $60 \% \pm 8.73 \%$ and $90 \% \pm 5.41 \%$, respectively (Figures $3 a$ and b), significantly lower than those from $\mathrm{FAH}^{+} \mathrm{FoxM} 1^{+}$ hepatocytes at all time points that the activity of liver repopulation had not completed. Expression of both $\mathrm{FAH}$ and FoxM1 protein was proven in the repopulated livers by western blots (Figure $3 \mathrm{c}$ ). Therefore, the enhanced capacity of liver repopulation of $\mathrm{Fah}^{-1-}$ mice reflected the enhanced cell expansion capacity of the hepatocytes with SB delivered FoxM1 gene. Moreover, results of functional studies indicated that the levels of aspartate aminotransferase, alanine transaminase and total bilirubin of FoxM1 hepatocytes recipients were recovered to normal ranges (Figure $3 \mathrm{~d}$ ), suggesting that the liver functions of mice recipients were effectively restored.

Next, we analyzed whether FoxM1 gene delivered by SB could enhance liver repopulation after partial hepatectomy. $\mathrm{Fah}^{-1-}$ mice were maintained on continuous NTBC, which maintains the liver in a healthy state. ${ }^{24}$ In all, $2 \times 10^{5} \mathrm{FAH}^{+}$ FoxM1 ${ }^{+}$hepatocytes or the same amount of WT hepatocytes were transplanted into healthy $\mathrm{Fah}^{-1-}$ mice that underwent 2/3 PHx, with NTBC provided throughout. Results of costaining of $\mathrm{FAH}$ and FoxM1 protein expression levels showed that the 2/3 $\mathrm{PHx}$ livers were significantly repopulated by $\mathrm{FAH}^{+} \mathrm{FoxM}^{+}$hepatocytes (Figure 3e). Results of $\mathrm{FAH}$ immunoassay revealed that $\mathrm{FAH}^{+} \mathrm{FoxM} 1^{+}$hepatocytes amounted up to $15.6 \%$ of total hepatocytes (range 5.8 to $15.6 \%$, average $6.16 \%$ at 3 weeks and from 4.5 to $11.8 \%$ average $7.02 \%$ at 6 weeks). In comparison, significant lower 
a
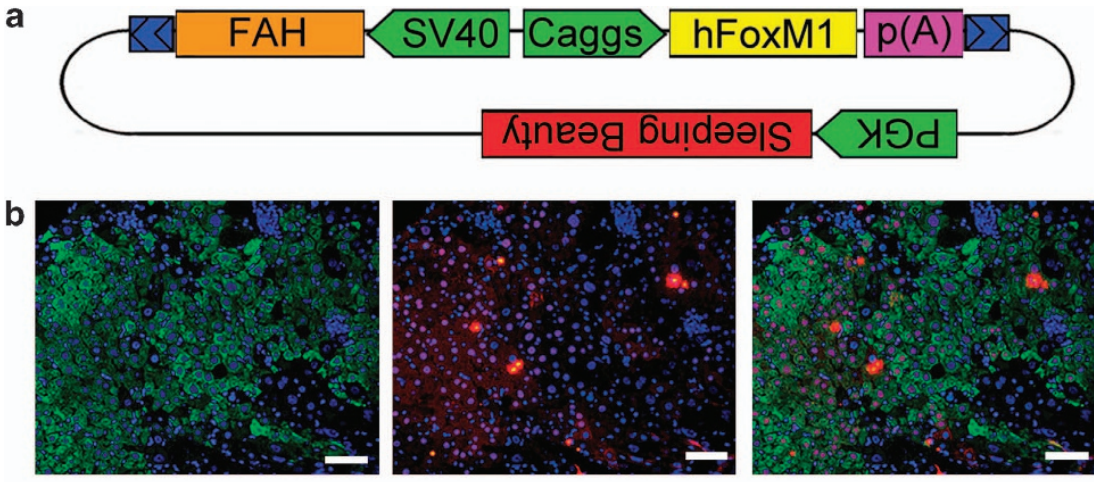

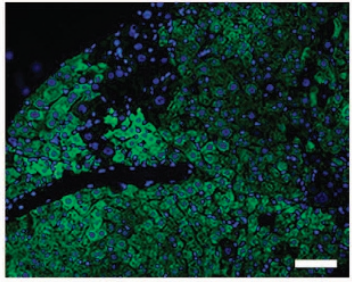

$\mathrm{FAH}$

C
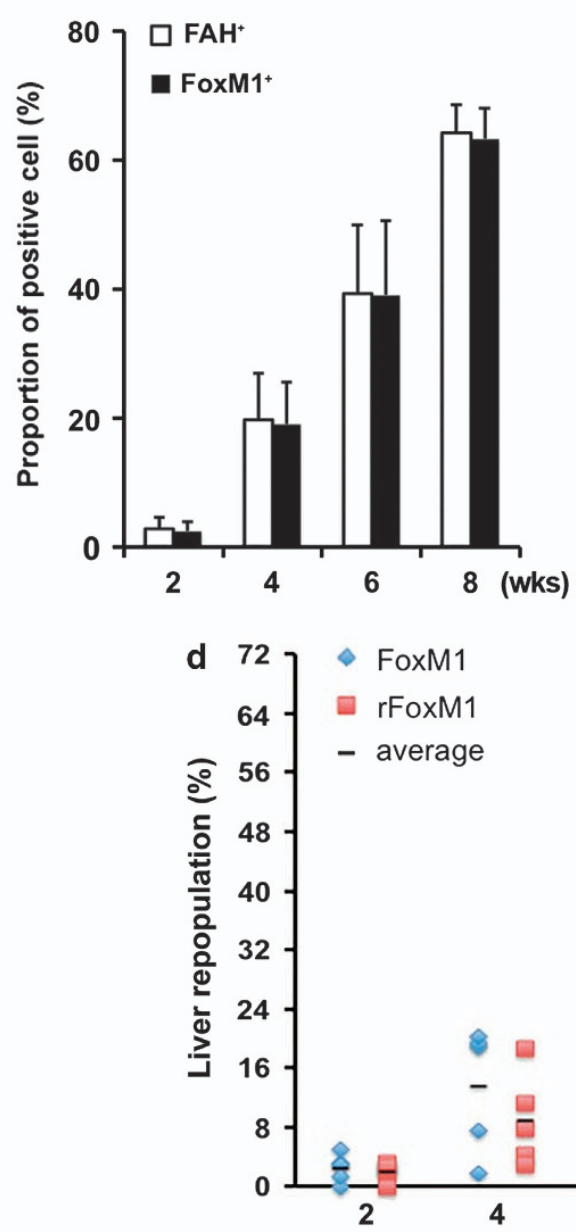

hFoxM1
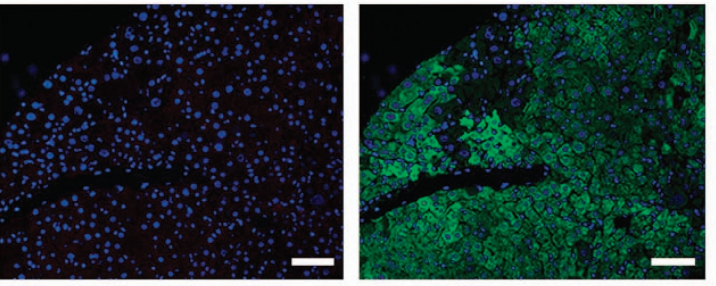

Merged
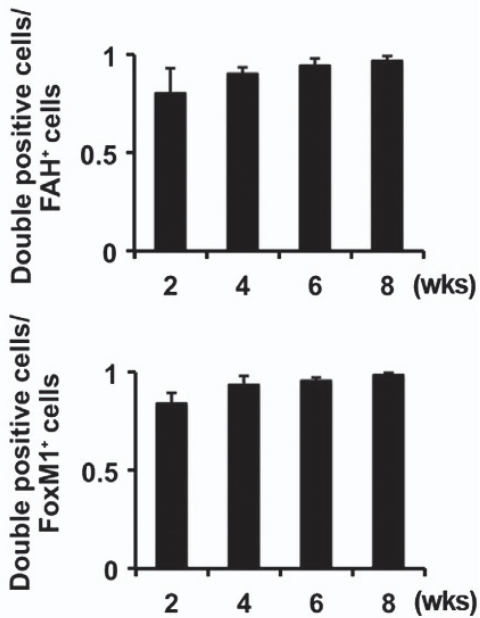

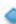

$\odot$

$\therefore$
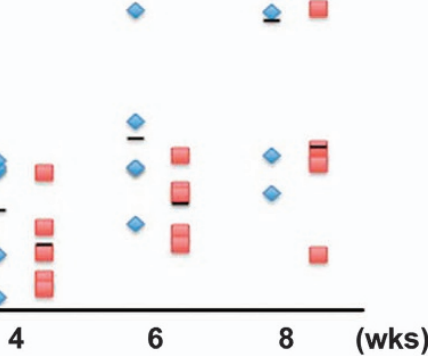

Figure 2 SB transposon system was effective in delivering FoxM1 gene into hepatocytes. (a) The SB plasmid constructions for delivery of Fah and FoxM1 genes into $\mathrm{Fah}^{-1-}$ hepatocytes, while plasmid with Fah and reversed FoxM1 (rFoxM1) genes as control. (b) Anti-FAH and anti-FoxM1 IHF co-staining in the livers 8 weeks after tail vein injection of FoxM1 plasmid (FAH ${ }^{+}$FoxM1 ${ }^{+}$, upper), and control plasmid (FAH ${ }^{+} \mathrm{FoxM1}{ }^{-}$, lower). Scar bar: $200 \mu \mathrm{m}$. (c) The proportions of FAH ${ }^{+}$and FoxM1 ${ }^{+}$in liver sections (left), and the proportions of double-positive cells in $\mathrm{FAH}^{+}$cells (right up) as well as in FoxM1 ${ }^{+}$cells (right down) were counted. (d) Liver repopulations were examined by anti-FAH IHC at 2, 4, 6 and 8 weeks after injection of FoxM1 or reversed FoxM1 plasmid 
a
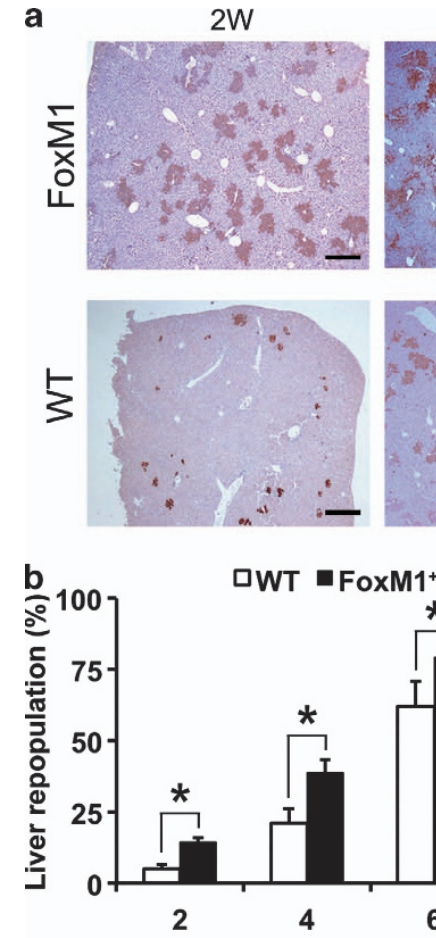

$4 \mathrm{~W}$
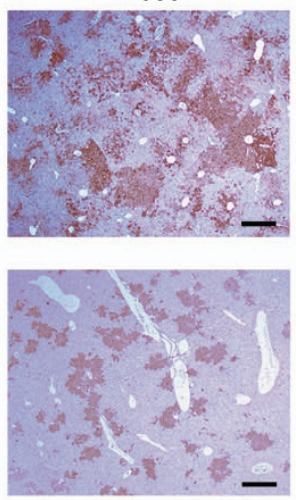

$1^{+}$

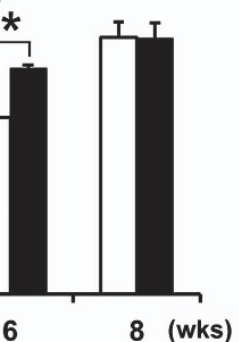

$6 \mathrm{~W}$
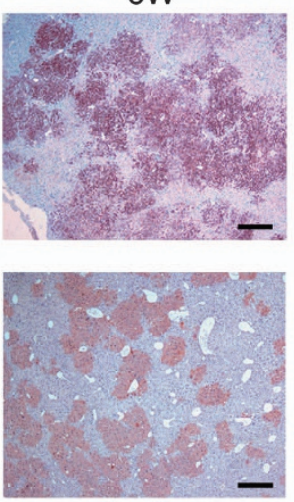

C

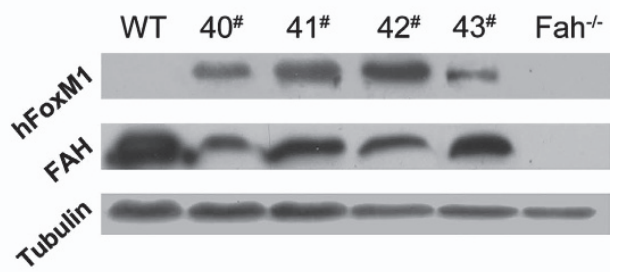

d

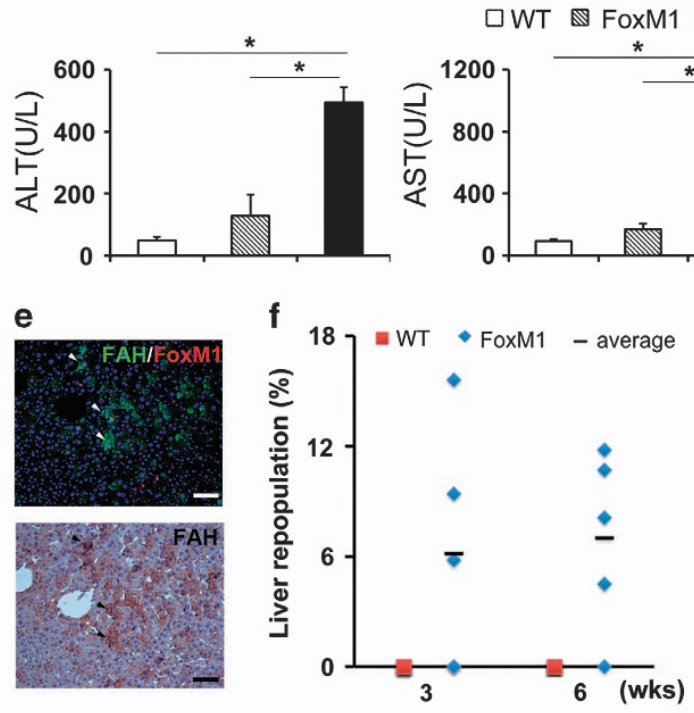

$\square$ WT $\mathbb{B}$ FoxM1 $\square \mathrm{Fah}^{-1-}$

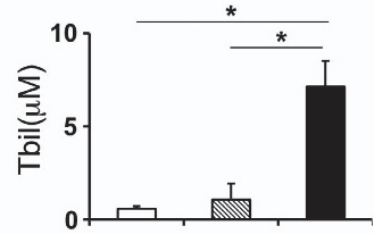

g $3 W$

$6 \mathrm{~W}$
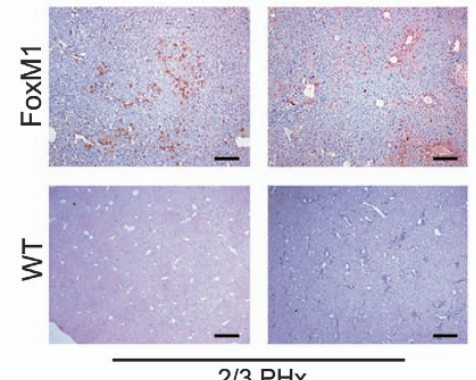

Figure 3 FoxM1-overexpressing hepatocytes modified with non-viral vector possess enhanced capacity of liver repopulation. (a and $\mathbf{b})$ Liver repopulations were detected by calculating the ratio of $\mathrm{FAH}^{+}$area in whole liver sections at 2, 4, 6 and 8 weeks after transplantation of $2 \times 10^{5} \mathrm{FoxM1} 1^{+}$or WT hepatocytes. (c) Western blot of liver samples showed FAH and hFoxM1 protein expressed in repopulated hepatocytes after FoxM1 plasmid injection. (WT: WT mice; 40\#, 41\#, 42\# and 43\#: four mice received FoxM1 plasmid injection and withdraw NTBC for 8 weeks; Fah $^{-1-}:$ Fah $^{-1-}$ mice). (d) Biochemical analysis of metabolic function of Fah ${ }^{-1-}$ recipients. The levels of alanine transaminase (ALT), aspartate aminotransferase (AST) and total bilirubin in WT mice $(n=4)$, Fah ${ }^{-1}$ recipients repopulated by FoxM1 ${ }^{+}$hepatocytes $(n=5)$, and Fah ${ }^{-1-}$ mice off NTBC and no hepatocyte transplantation $(n=4)$ are shown. Data represented as mean \pm S.D. ${ }^{*} P<0.05$. (e) Co-staining of FAH and FoxM1 in the liver sections showed host liver was repopulated by FAH ${ }^{+}$FoxM1 ${ }^{+}$hepatocytes in Fah ${ }^{-1-}$ mice maintained with NTBC and received 2/3 PHx. (f) In histogram, FAH ${ }^{+}$cells was used to assess repopulation rate in recipient livers 3 and 6 weeks after transplantation of $2 \times 10^{5} \mathrm{FoxM} 1^{+}$or WT hepatocytes. (g) IHC of FAH in the liver sections from FoxM1 ${ }^{+}$or wild-type hepatocytes repopulation. Scar bar: $500 \mu \mathrm{m}$

levels of engraftment $(<1 \%)$ were found with WT hepatocytes transplanted mice after in $\mathrm{PHx}$ (Figures $3 f$ and $\mathrm{g}$ ).

In addition, the $\mathrm{FAH}^{+}$FoxM1 ${ }^{+}$hepatocytes were cultured and detected for DNA replication by using the time course of BrdU incorporation. The result indicated that during $24-48 \mathrm{~h}$ of cell culture, more FoxM1 ${ }^{+}$hepatocytes than WT hepatocytes incorporated BrdU, indicating a faster entry into S-phase by FoxM1 ${ }^{+}$cells (Figure 4a).

Ki67 and proliferating cell nuclear antigen (PCNA) were used as cell proliferation markers to further evaluate the proliferation rate in order to confirm the result of BrdU incorporation. The $\mathrm{Ki}_{67}{ }^{+}$cells in total FoxM1 ${ }^{+}$hepatocytes 

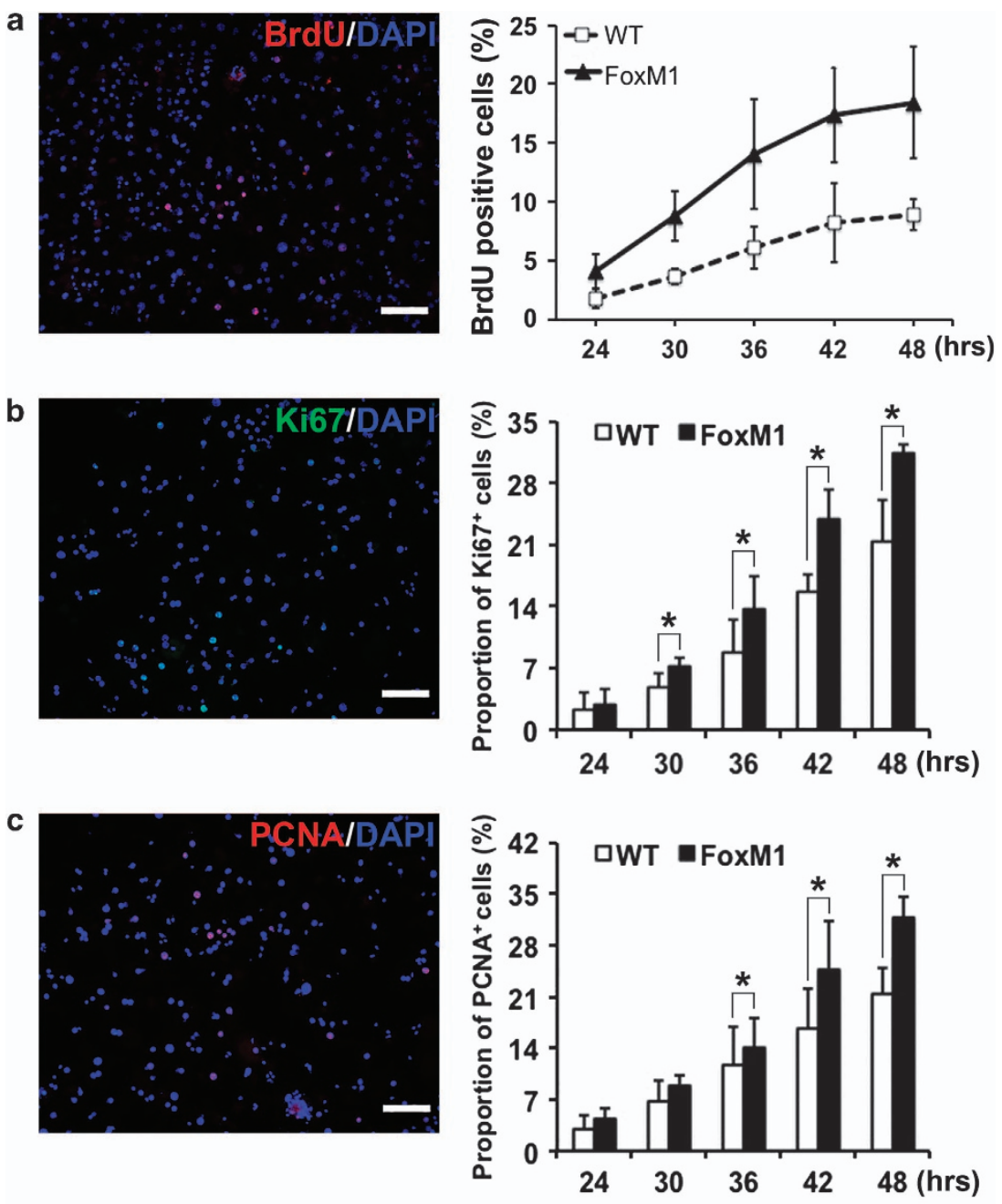

d

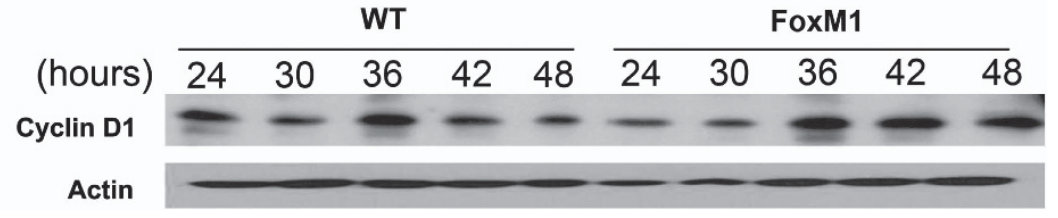

Figure 4 Enhanced cell expansion capacity of hepatocytes with FoxM1 expression. (a) DNA replications were assessed by time course BrdU incorporation during primary cell culture of hepatocytes isolated from mice received FoxM1 plasmid injection. The percentage of BrdU ${ }^{+}$hepatocyte was calculated for each time point of the culture. The sharp slope of FoxM1 ${ }^{+}$hepatocytes reflected faster BrdU incorporation compared with WT hepatocytes. (b and $\mathbf{c}$ ) Cultured primary hepatocytes expressing Ki67 or PCNA were labeled by immunocytofluorescence (left), and the positive rates in each time point were calculated (right). Data represented as mean \pm S.D. Scar bar: $200 \mu \mathrm{m}$. ${ }^{*} P<0.05$. (d) Expression levels of Cyclin D1 in cultured primary hepatocytes were detected by western blot

were significantly higher than those in WT hepatocytes after $30 \mathrm{~h}$ of culture. The same result was also obtained from the experiments with proportions of PCNA (Figures $4 b$ and $c$ ). However, the expression levels of cyclin D1 in every time point were not elevated (Figure 4d), same as finding in a previous report. ${ }^{25}$ These results showed a consistent enhancement of FoxM1 hepatocyte expansion was induced by the activation of pathway relative to Ki67 and PCNA, but not Cyclin D1. ${ }^{25}$

Liver repopulation by hepatocytes with ex vivo FoxM1 gene delivery by SB vector. Modified hepatocytes with an enhanced proliferation capacity could be used for cell transplantation therapy in the future. Ex vivo gene delivery of FoxM1 by SB vector into hepatocytes was tested in our experiment. The SB vector of pKT2/GFP-hFoxM1-SB, which contains FoxM1 and GFP genes, was constructed and used to transfect freshly isolated WT hepatocytes in cell culture. $\mathrm{GFP}^{+} \mathrm{FAH}^{+} \mathrm{FoxM1}^{+}$and $\mathrm{GFP}^{-} \mathrm{FAH}^{+} \mathrm{FoxM}^{-}$hepatocytes, representing transfected and un-transfected cells respectively, were mixed after transfection. The $\mathrm{GFP}^{+}$ hepatocytes in total cells were determined by flow cytometry at $24 \mathrm{~h}$ after transfection, and the percentage of $\mathrm{GFP}^{+}$ hepatocytes in two separate experiments were $10.0 \%$ and $10.9 \%$ respectively (Figure $5 a$ ).

In all, $2 \times 10^{5}$ mixed cells, including $\mathrm{GFP}^{+}$and $\mathrm{GFP}^{-}$ hepatocytes, were transplanted into $\mathrm{Fah}^{-1-}$ mice. NTBC was 

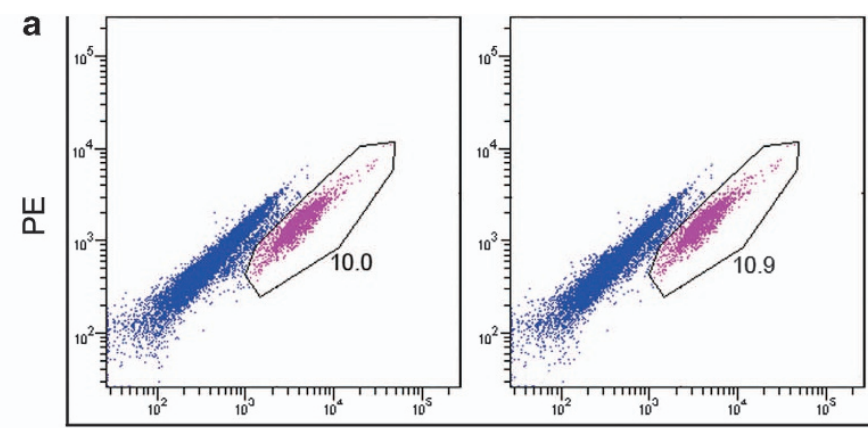

GFP
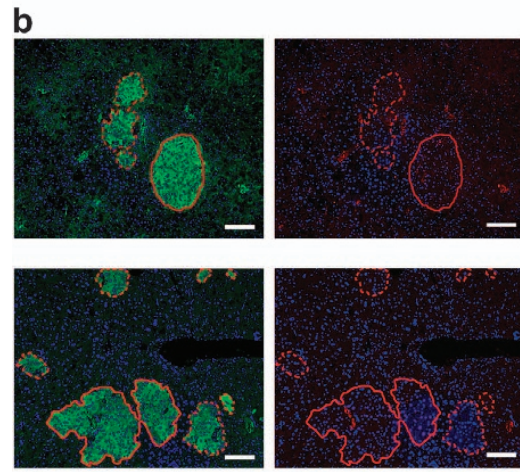

$\mathrm{FAH}$

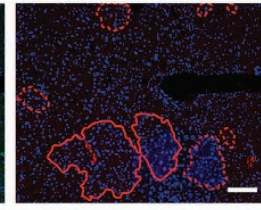

hFoxM1
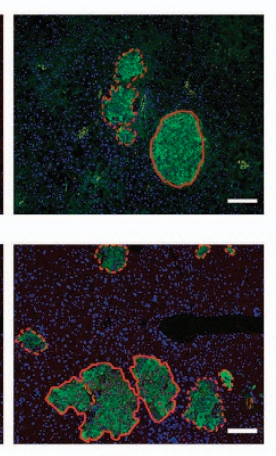

Merged

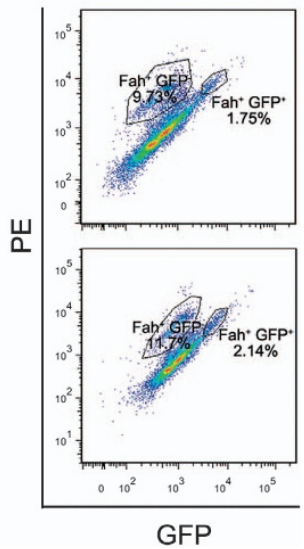

Figure 5 Enhanced capacity of liver repopulation acquired by transfecting FoxM1 plasmid in vitro. (a) Freshly isolated WT hepatocytes were transfected with hFoxM1 plasmid and cultured for $24 \mathrm{~h}$. The transfection efficiencies of two separate experiments were analyzed by FACS by gating the GFP ${ }^{+}$cells. (b) Transfected hepatocytes were transplanted into $\mathrm{Fah}^{-1-}$ mice. Six weeks after transplantation, liver tissues of recipients were harvested for anti-FAH and anti-FoxM1 IHF (solid lines: FAH ${ }^{+}$FoxM1 ${ }^{+}$ nodules; dotted line: $\mathrm{FAH}^{+}$FoxM1- nodules). Hepatocytes isolated from livers of recipients for FACS detecting anti-FAH (PE) and GFP. Data from one recipient in each experiment were shown. Scar bar: $200 \mu \mathrm{m}$

withdrawn to induce liver repopulation. Results from liver samples at 6 weeks after transplantation revealed that $\mathrm{FAH}^{+}$ FoxM1 ${ }^{+}$nodules (solid lines) were larger in size than $\mathrm{FAH}^{+}$ FoxM1 ${ }^{-}$nodules (dotted lines), indicating that hepatocytes containing the FoxM1 gene had a higher proliferation rate than WT hepatocytes (Figure 5b). Next, hepatocytes were isolated from the livers of recipients, incubated with anti-FAH antibody and PE-conjugated secondary antibody, and analyzed for percentage of $\mathrm{FAH}^{+}$and GFP ${ }^{+}$hepatocytes by flow cytometry. The results showed that $\mathrm{FAH}^{+}$hepatocytes reached $12.42 \pm 0.77 \%$, and $\mathrm{GFP}^{+}$hepatocytes reached $1.87 \pm 0.15 \%$ of the total. As described previously, ${ }^{26}$ the percentage of GFP ${ }^{+}$ cells detected by FACS was normalized by the following equation: $\left(\% \mathrm{GFP}^{+}\right) /\left(\% \mathrm{FAH}^{+}\right) \times 100$. Expansion of $\mathrm{GFP}^{+}$ cells was calculated as follows: ( $\%$ normalized GFP ${ }^{+}$after repopulation $) /\left(\% \mathrm{GFP}^{+}\right.$cells originally transplanted). Analyzed by this method, FoxM1 ${ }^{+}$hepatocytes (GFP ${ }^{+}$cells) proliferated at higher rate than WT hepatocytes (1.44 \pm 0.04 fold) (Table 1), which indicates that hepatocytes with ex vivo gene delivery of FoxM1 had an enhanced capacity for liver repopulation. This method provides a more practical and convenient way to upregulate FoxM1 expression in the isolated donor cells in vitro for future clinical applications.

FoxM1 ${ }^{+}$hepatocytes did not form tumors. The risk of cancer formation is a concern for any therapies that involve integration in the genome and enhancement of cell proliferation. To evaluate the safety of overexpressing FoxM1, we serially isolated and transplanted FoxM1-expressing hepatocytes at 8-week intervals up to four times, resulting in continuous proliferation of the cells for 8 months. No tumor was found in all tissues of the mice recipients, and the livers of recipients kept in the normal morphological structure and size with healthy sinusoidal plates (Figure 6a). Particularly, liver tissues repopulated by TTR-FoxM1 hepatocytes showed normal liver sinusoidal structures without any morphological abnormalities although TTR-FoxM1 hepatocytes divided at least 44 times during the four rounds of serial transplantations (Figure 6a). Furthermore, hepatocytes isolated from TTR-FoxM1 mice did not form tumors 12 weeks after subcutaneous xenograft in NOD/SCID mice (Figure 6b). We observed similar results with $\mathrm{FoxM} 1^{+}$hepatocytes delivered using SB gene delivery. In all, $20 \mathrm{Fah}^{-/-}$mice injected with FoxM1-SB plasmids, the livers showed normal morphological structure and size, and no tumor were found in all liver samples harvested at 8 weeks (Table 2), even with repopulation levels as high as $68.03 \%$ (Figure 6c). In addition, no tumor was found in any secondary recipient mice until 18 months after transplantation when liver repopulation totally completed in liver of recipients (Table 2).

In addition, gene expression levels were analyzed in repopulation nodules of $\mathrm{FAH}^{+}$hepatocytes. The $\mathrm{FAH}^{+}$ 
Table 1 FoxM1-overexpressing hepatocytes proliferated at higher rate than WT hepatocytes

\begin{tabular}{|c|c|c|c|c|c|c|}
\hline Transplant \# & Input WT \% & Input GFP \% & Output GFP \% & $\mathrm{FAH}^{+} \%$ & Output normalized GFP \% & GFP ratio (output/input) \\
\hline 1 & 90 & 10 & 1.75 & 11.64 & 15.03 & 1.50 \\
\hline 2 & 90 & 10 & 1.79 & 12.39 & 14.45 & 1.44 \\
\hline 3 & 90 & 10 & 1.76 & 12.16 & 14.47 & 1.45 \\
\hline 4 & 89.1 & 10.9 & 1.95 & 12.55 & 15.54 & 1.43 \\
\hline 5 & 89.1 & 10.9 & 1.81 & 11.91 & 15.20 & 1.39 \\
\hline \multirow[t]{2}{*}{6} & 89.1 & 10.9 & 2.14 & 13.84 & 15.46 & 1.42 \\
\hline & & & & & Average \pm S.E.M. & $1.44 \pm 0.04$ \\
\hline
\end{tabular}

The percentage of $\mathrm{GFP}^{+}$cells detected by FACS was normalized across all experiments by the following equation: $\left(\% \mathrm{GFP}^{+}\right) /\left(\% \mathrm{FAH}^{+}\right) \times 100$. Expansion of GFP ${ }^{+}$ cells was calculated as follows: (\% normalized GFP ${ }^{+}$after repopulation)/(\% GFP ${ }^{+}$cells originally transplanted). Relative to wild-type transplanted hepatocytes, GFP $^{+}$hepatocytes expanded $1.44 \pm 0.04$-fold $(n=5$ mice $)$. This result indicates that FoxM $1^{+}$hepatocytes proliferate capacity is 1.44 -fold of wild-type hepatocytes in vivo

nodules were isolated by laser-captured microdissection $(\mathrm{LCM})^{27}$ (Figure 6d). Results revealed that oncogene Myc, as well as the markers of hepatocellular carcinoma enriched genes, Erbb3 ${ }^{28,29}$ and Afp, had much lower expression levels in both WT hepatocytes and FoxM1 ${ }^{+}$hepatocytes after repopulation, in comparison with those levels in liver tumors formed after subcutaneous injection of Hepa1-6 cells (Figure 6e). Results suggested that the enhanced FoxM1 expression in repopulating hepatocytes did not induce the concern of the risk for tumorigenesis.

Therefore, these results confirmed that there was no the risk of tumorigenesis with SB-mediated FoxM1 delivery during the span of our experiments in the liver injury models and immunodeficient animals.

\section{Discussion}

Previous clinical trials of hepatocyte transplantation suggest that a level of $>2 \%$ engraftment is necessary to reach therapeutic benefit for different metabolic disorders. ${ }^{3,30}$ However, at present it is hard to reach such level with unmodified human hepatocytes. ${ }^{3}$ Recent publications showed increased engraftment after irradiation to inhibit host hepatocyte proliferation, ${ }^{31}$ or 4-[(2-carboxyethyl)-hydroxyphosphinyl]-3-oxobutyrate (CEHPOBA) as metabolic enzyme inhibitor to simulate metabolism disorders. ${ }^{32}$ But those methods also may have strong side effects to patients. In comparison, using a regulator of cell cycle to modify donor hepatocytes is a more promising approach.

FoxM1 was chosen in our study for its ability to accelerate the cell cycle in donor hepatocytes during liver regeneration without tumorigenesis. ${ }^{33}$ On the other hand, a safe and reliable gene delivery system is another important issue to be considered in our study. The non-viral SB transposon/ transposase system has many advantages over other nonviral DNA vectors, ${ }^{34}$ such as higher transgene integration rate, without plasmid sequences integration that silence transgene expression and no integration of transgene concatemers. Especially, the high cargo capacity of SB vector system ${ }^{35}$ allowed our designed construct for ideal delivery and sustained FoxM1 expression. In the previous reports, ${ }^{22}$ the transfection efficiency of SB transposon system was known approximately $2 \%$, which was defined as the rate of DNAs inserted into genome of liver cells. Our transfection efficiency of SB delivered FoxM1 was similar to previous reports. ${ }^{36}$ Here, the selection of donor hepatocytes from liver regeneration mechanism during liver injury, such as in $\mathrm{Fah}^{-1-}$ mice and in 2/3 PHx mice, made an efficient expansion of FoxM1 ${ }^{+}$ hepatocytes in the host livers. The result suggested the potential advantage could be obtained from the combination of enhanced cell proliferation by FoxM1-SB gene delivery and selection power of liver repopulation, which could become the potential future clinical application.

Previous studies indicated that 2/3 partial hepatectomy, used in combination with cell transplantation, promoted engraftment and cell expansion of transplanted donor hepatocytes. We found that mice undergoing PHx showed much higher liver engraftment from FoxM1 ${ }^{+}$hepatocytes than from WT hepatocytes. Moreover, our results revealed that enhanced capacity of cell proliferation for FoxM1 ${ }^{+}$ hepatocytes greatly reduced the amount of time needed to complete liver repopulation in $\mathrm{Fah}^{-1-}$ mice, which could be considered as an advantage to using FoxM1 in future applications.

Our study also indicated that the FoxM1 enhanced hepatocyte proliferation during liver repopulation was through both PCNA and Ki67 involved signaling pathway, but not cyclin D1 involved one. Our finding is same with results of previous report. ${ }^{25}$ We presumed that the possible mechanism of FoxM1 in acceleration of G2/M phase transition could be by stimulating the cell cycle regulators other than cyclin D1.

Although it was previously shown in TTR-FoxM1 transgenic mice that hepatocytes with expression of FoxM1 did not have an elevated incidence of tumors for hepatocellular carcinoma during induction, ${ }^{33}$ it was not proved yet whether transplanted hepatocytes with constitutive FoxM1 expression, undergoing extensive liver repopulation, would form tumors. Furthermore, hepatocytes with transposonmediated delivery of FoxM1 should be studied carefully for tumorigenicity before consideration for future clinical application. Therefore, we deeply analyzed the tumorigenesis from the TTR-FoxM1 hepatocytes undergoing continuous cell division by serial transplantation. Our results showed that there were no tumors formed in any recipient mice and no morphological abnormalities in TTR-FoxM1 hepatocytes. In addition, TTR-FoxM1 hepatocytes did not form any tumor after subcutaneous xenograft in NOD/SCID mice. In our study, we also had broad scanning of the sufficient liver samples from the recipients with high level of liver repopulation after FoxM1 SB plasmid injection. On the other hand, we have not found the existence of risk of tumorigenesis in 

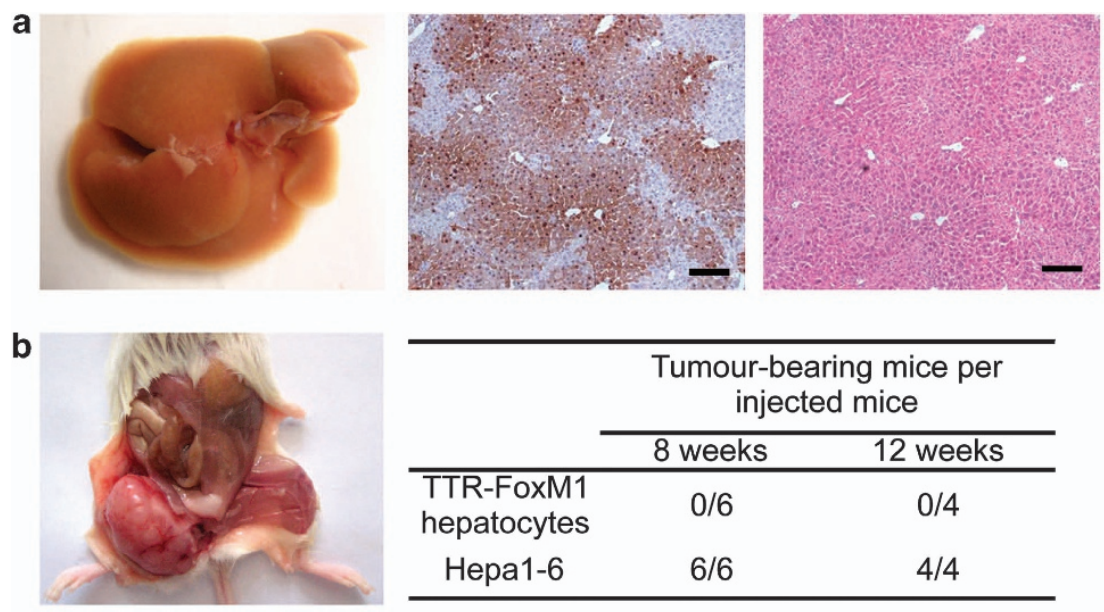

\begin{tabular}{ccc}
\hline & \multicolumn{2}{c}{$\begin{array}{c}\text { Tumour-bearing mice per } \\
\text { injected mice }\end{array}$} \\
\cline { 2 - 3 } & 8 weeks & 12 weeks \\
\hline $\begin{array}{c}\text { TTR-FoxM1 } \\
\text { hepatocytes } \\
\text { Hepa1-6 }\end{array}$ & $0 / 6$ & $0 / 4$ \\
\hline
\end{tabular}

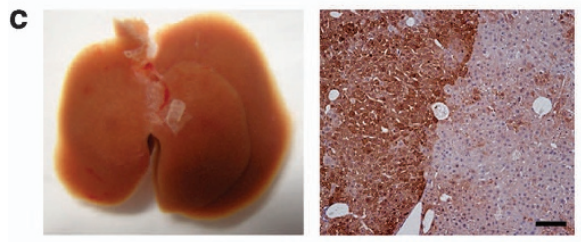

d

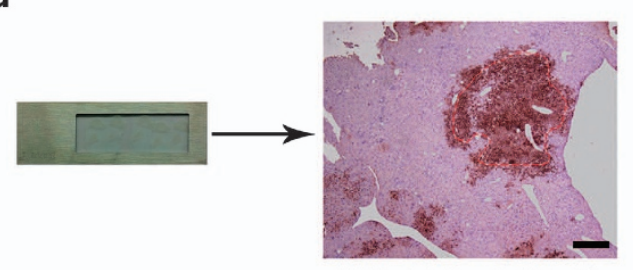

FAH staining to identify

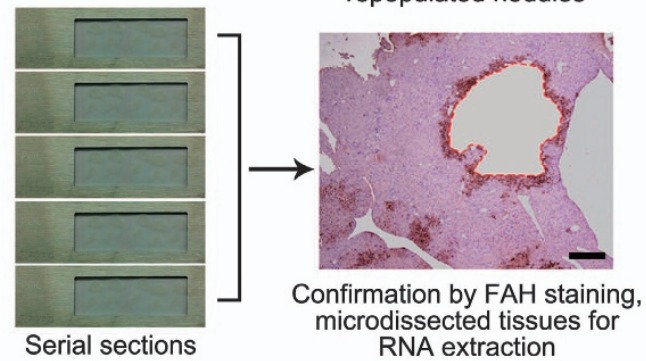

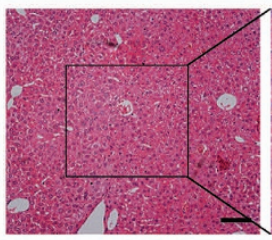

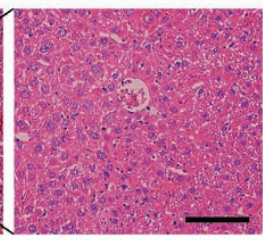

e
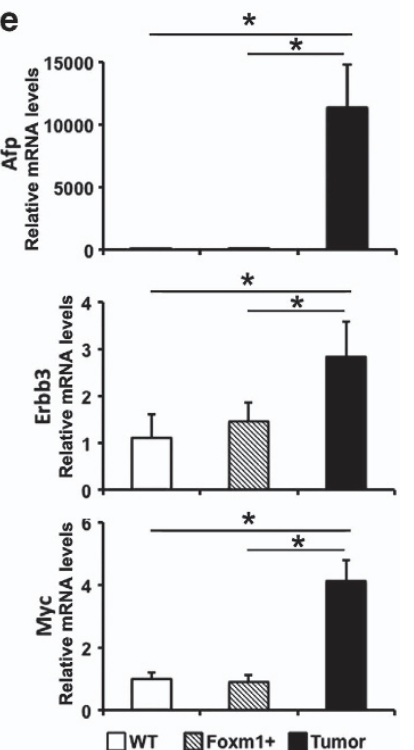

Figure 6 FoxM1-overexpressing hepatocytes did not increase the risk of tumorigenesis. (a) After four rounds of serial transplantation, the livers of recipient mice were still in normal shape and size with smooth surface. Anti-FAH IHC and serial hematoxylin and eosin (H\&E) staining of liver samples show no morphological abnormality. (b) TTRFoxM1 hepatocytes and Hepa1-6 cells (human hepatoma cell line) were subcutaneously transplanted into the left and right flanks of NOD/SCID mice, respectively. All mice received Hepa1-6 cells formed tumors, while none of mice received TTR-FoxM1 hepatocytes were bearing tumor 8 weeks or even 12 weeks after transplantation. (c) Liver of recipients showed normal shape and size. Anti-FAH IHC and H\&E staining of liver samples from Fah ${ }^{-l-}$ mice were examined at 8 weeks after FoxM1 plasmid injection. (d) Schema of $\mathrm{LCM}$. FAH ${ }^{+}$nodules were isolated by $\mathrm{LCM}$ from serial liver sections. Tissues from the same $\mathrm{FAH}^{+}$nodules were pooled for mRNA extraction. Scar bar: $500 \mu \mathrm{m}$. (e) mRNA expression of Afp, Erbb3 and Myc were measured from isolated FAH ${ }^{+}$nodules. Data represented as mean \pm S.D. ${ }^{*} P<0.05$

FoxM1 ${ }^{+}$hepatocytes even at 18 months after the gene delivery.

We have found an efficient method to genetically modify primary hepatocytes by SB vector delivery. Hepatocytes with FoxM1 expression demonstrated the enhanced capacity of proliferation in both in vitro and in vivo. We also expect that this method can be used for modifying other hepatic cells, such as hepatocytes derived from ES/iPS cells, ${ }^{37,38}$ hepatocytes or hepatic stem cells trans-differentiated from other kinds of cells, ${ }^{27,39}$ which are being studied for future applications of cell transplantation therapy.

\section{Materials and Methods}

Mouse strains and animal husbandry. TTR-FoxM1 transgenic mice were kindly provided by Dr. Robert Costa. Fah ${ }^{-1-}$ and Fah ${ }^{-1-}$ Rag2 ${ }^{-1-}$ mice were maintained with drinking water containing NTBC at a concentration of $7.5 \mu \mathrm{g} / \mathrm{ml}$. 
Table 2 Tumor formation after FoxM1-SB plasmid injection

\begin{tabular}{lcc}
\hline & \multicolumn{2}{c}{$\begin{array}{c}\text { Tumor-bearing mice per } \\
\text { mice in experiment }\end{array}$} \\
\cline { 2 - 3 } $2-8$ Weeks & 18 Months \\
\hline FoxM1 plasmid injection & $0 / 20$ & ND \\
FoxM1 hepatocytes transplantation & $0 / 25$ & $0 / 5$ \\
\hline
\end{tabular}

Twenty Fah ${ }^{-1-}$ mice received FoxM1-SB plasmid injection and none of them formed tumor 2-8 weeks after injection. The hepatocytes were isolated and transplanted into secondary $\mathrm{Fah}^{-1-}$ mice for analyzing liver repopulation capacity. Thirty mice were transplanted with FoxM1-SB hepatocytes and none of them grew any tumor even until over 18 months after transplantation

All mice were housed in individually ventilated cage system under special pathogen-free facility with barrier conditions, and animal care was in accordance with institutional guidelines.

Hepatocytes isolation, competitive repopulation experiment, partial hepatectomy surgery, serial transplantation and FACS. Mice were subjected to standard two-step collagenase perfusion for primary hepatocytes isolation. Parenchymal cells were purified by Percoll buffer $(90 \%$ Percoll (Sigma-Aldrich, St. Louis, MO, USA), EBSS) at low-speed centrifugation (1500 r.p.m., $10 \mathrm{~min}$ ). Viability of isolated hepatocytes was determined by Trypan blue stain.

In competitive repopulation experiments, mixed hepatocytes (TTR-FoxM1 hepatocytes: $\beta$-gal ${ }^{+}$hepatocytes $\left.=1: 1\right)$ were transplanted into Fah $^{-1}$ Rag$2^{-1-}$ mice. At 2, 4, 6 and 8 weeks after transplantation, liver tissues were harvested from recipients for analysis by Southern blot. Liver genomic DNA was isolated from random sections of tissue from the left main lobe. Genomic DNAs were digested with BamHI (Takara, Dalian, China) and separated by $0.8 \%$ agarose gel. Capillary transfer and hybridization were performed according to standard protocols. Detection of FoxM1 and LacZ genes indicate repopulation contributed by TTR-FoxM1 and Rosa26-LacZ hepatocytes, respectively.

For serial transplantation, TTR-FoxM1 hepatocytes were isolated from the liver of primarily transplanted $\mathrm{Fah}^{-1-}$ Rag- $2^{-1-}$ mice at 8 weeks when complete liver repopulation has reached. The $10^{5}$ TTR-FoxM1 hepatocytes from primary recipient were transplanted into the secondary recipients of Fah ${ }^{-1-}$ Rag- $2^{-1-}$ mice, and the second round of liver repopulation was studied. After next 8 weeks, TTR-FoxM1 hepatocytes were harvested again and re-transplanted into third group of $\mathrm{Fah}^{-1-}$ Rag-2 ${ }^{-1-}$ mice. Serial transplantation lasted four rounds.

PHx was acted as described. ${ }^{40}$ In all, $2 \times 10^{5}$ hepatocytes were injected immediately into the spleens of mice recipients. Fah ${ }^{-1-}$ mice that was subjected to $\mathrm{PHx}$ were maintained with NTBC. To those recipients without PHx, NTBC was withdrawn from the drinking water after cell transplantation.

For FACS, hepatocytes were harvested and washed twice in washing buffer (phosphate-buffered saline containing $0.2 \% \mathrm{BSA}$ ). In all, $10^{5}$ cells were stained in $100 \mu \mathrm{l}$ washing buffer with chromophore-conjugated antibodies at $4^{\circ} \mathrm{C}$ for $30 \mathrm{~min}$, washed twice and analyzed. Primary antibody-bound cells were further incubated with PE-conjugated secondary antibodies at $4{ }^{\circ} \mathrm{C}$ for $30 \mathrm{~min}$, washed twice and analyzed. Isotope antibodies were used as negative controls. Cells were harvested and washed twice. Cells were analyzed using a FACS Calibur flow cytometer (Becton Dickinson, San Jose, CA, USA) and data analyzed via FlowJo software (Tree Star, Ashland, OR, USA).

Plasmids construction, tail vein injection and in vitro transfection. We modified the plasmid, pKT2/FAH-IRES-Luc-SB, described in our previous study 22 to construct plasmid for transporting FoxM1. Human FoxM1 gene was cloned and substituted Fah gene to get pKT2/hFoxM1-IRES-Luc-SB. Then SV40-FAH was inserted into the plasmid to construct pKT2/FAH-hFoxM1-IRESLuc-SB. IRES-Luc was cut off from plasmid pKT2/FAH-hFoxM1-IRES-Luc-SB. Plasmid pKT2/FAH-hFoxM1-SB were used for transport FoxM1 and Fah genes into hepatocytes by tail vein injection. Luciferase gene in pKT2/hFoxM1-IRES-Luc$\mathrm{SB}$ was substituted with GFP gene to get the plasmid used in in vitro transfection. For tail vein injection, $30 \mathrm{~g}$ high-quality plasmid diluted in $1 / 10$ body weight Ringer's solution, injected into $\mathrm{Fah}^{-1-}$ mice through tail vein within $10 \mathrm{~s}$. Highly purified plasmid was transfected into fresh isolated WT hepatocytes with
Amaxa-Mouse/Rat-Hepatocyte-Nucleofector-Kit (Lonza, Basel, Switzerland) followed the optimized protocol from manual.

IHC and immunohistofluorescence. Immunohistologic detection of $\mathrm{FAH}$, as well as hematoxylin and eosin staining were preformed. Liver samples were fixed in $4 \%$ paraformaldehyde before paraffin embedding. Sections $(2 \mu \mathrm{m})$ were de-paraffin with xylene, rehydrated, incubated with rabbit anti-mouse Fah primary antibody (HepatoScience, San Jose, CA, USA) at $37^{\circ} \mathrm{C}$ for $1 \mathrm{~h}$, then horseradish peroxidase-conjugated goat anti-rabbit immunoglobulin $\mathrm{G}$ secondary antibody, followed by detection with DAB (Dako, Glostrup, Denmark) and counterstaining with Mayer's hematoxylin solution (Sigma-Aldrich).

Donor cells and their descendants were labeled by anti-FAH IHC. Liver repopulation rates were evaluated by calculating the ratio of $\mathrm{FAH}^{+}$area in whole liver sections.

For immunohistofluorescence, sections were incubated with rabbit anti-mouse Fah $A B$ mixed with mouse anti-human FoxM1 primary antibody (Abcam, Cambridge, MA, USA), followed by donkey anti-rabbit Dylight 488 -conjugated and goat anti-mouse Dylight549-conjugated secondary antibody at $37^{\circ} \mathrm{C}$ for half an hour in dark. Nuclei were stained with Dapi-Fluoromount-G (Sourthernbiotech, Birmingham, AL, USA).

Western blot. Western blot analysis was performed as previous publication. ${ }^{22}$ Liver total proteins were extracted from mouse liver tissues using Minute Total Protein Extraction Kit (Invent Biotechnologies, Eden Prairie, MN, USA). For detection of $\mathrm{FAH}$, rabbit anti-mouse $\mathrm{FAH}$ was used in combination with goat antirabbit IgG, HRP (Sigma-Aldrich). For detecting human FoxM1, rabbit anti-human FoxM1 (Lifespan, Seattle, WA, USA) was used as primary antibody with goat antirabbit IgG, HRP (Sigma-Aldrich) as secondary antibody. Mouse anti-cyclin D1 (Santa Cruz, Dallas, TX, USA) and goat anti-mouse IgG, HRP (Sigma-Aldrich) were used for detecting cyclin D1.

LCM, RNA extraction, reverse transcription polymerase chain reaction and quantitative polymerase chain reaction. $\mathrm{Fah}^{+}$ nodules were isolated by LCM (Leica Microsystems, Wetzlar, Germany; LMD6500) from serial liver sections. The first section was immunostained with anti-FAH antibody to locate the repopulated $\mathrm{FAH}^{+}$nodules in the recipient livers. $\mathrm{FAH}^{+}$tissues with the nodules were microdissected from the other sections. After microdissection, those leftover sections on the slides were further stained with anti-FAH antibody to confirm that only $\mathrm{FAH}^{+}$nodules were microdissected. Total RNA was extracted by RNeasy FFPE Kit (QIAGEN, RNeasy FFPE, Hilden, Germany) according to the manufacturer's instructions. One gram RNA was reverse transcribed into complementary DNA (CDNA) with random hexamers using First Strand cDNA Synthesis Kit (Promega, Madison, WI, USA). Quantitative polymerase chain reaction (Q-PCR) analysis was performed by SYBR Green Real-time PCR Master Mix (Takara) on an ABI7300 (Applied Biosystems, Life Technologies, Thermo Fisher Scientific, San Jose, CA, USA) real-time PCR machine. Housekeeping gene $\beta$-actin was used for normalization. The fold difference in expression was calculated as threshold cycle $(2 \Delta-C t)$. The primers used in Q-PCR were: myc, $3^{\prime}-5^{\prime}$ : ACGGAGTCGTAGTCGAGGTC, 5'-3': AGA GCTCCTCGAGCTGTTTG; erbb3, 3'-5': AGTGCGATTGGGACTCTGC, 5'-3': CTCCAGGTTACCCATGACCAC; afp, 3'-5': GCCACCGAGGAGGAAGTG, 5'-3': AGTCTTCTTGCGTGCCAGC; $\beta$-actin, 3'-5': TGAGCGCAAGTACTCTGTGTGG AT, 5'-3': ACTCATCGTACTCCTGCTTGCTGA.

Primary culture of hepatocytes, BrdU incorporation, Ki67 and PCNA staining. To analyze the proliferation rate of mouse hepatocytes, we used primary hepatocyte culture conditions as previously described. ${ }^{41}$ The percentage of cells undergoing DNA synthesis was estimated by counting the number of BrdU-labeled cells using the BrdU detection kit (Roche Diagnostics, Meylan, France). Cells were incubated with BrdU-labeling medium for $5 \mathrm{~h}$. The medium was then removed, and cells were fixed in ethanol/acetic acid $(7: 3)$ and stained according to the manufacturer's instructions. Ten separate fields per plate were counted.

Cultured primary hepatocytes were fixed by $4 \%$ PFA, stained by rabbit anti-Ki67 (Thermo Fisher Scientific) and mouse anti-PCNA (Thermo Fisher Scientific) primary antibody, followed by donkey anti-rabbit Dylight488-conjugated and goat antimouse Dylight549-conjugated secondary antibody (Jackson ImmunoResearch, West Grove, PA, USA) at $37^{\circ} \mathrm{C}$ for half an hour in dark. Nuclei were stained with Dapi-Fluoromount-G (Sourthernbiotech). The positive nuclei and DAPI in a field were counted, five separate fields per plate were counted. 
Statistical analysis. All data are presented as mean \pm S.D. For most statistical evaluation, a Student's $t$-test was applied in this study. For survival analysis, the Mantel-Cox log-rank test was applied. Statistical calculation was performed using Statistical Program for Social Sciences software (IBM SPSS, IBM Corporation, Somers, NY, USA). For all statistics, data from at least three independent samples or repeated experiments were used.

\section{Conflict of Interest}

The authors declare no conflict of interest.

Acknowledgements. This work was funded by National Key Basic Research and Development Program of China (2011CB966200, 2010CB945600), National Natural Science Foundation of China $(31271474,30801115,31171309,31271469$ 31271042, 31100996 and 30873457).

1. Grompe M. Therapeutic liver repopulation for the treatment of metabolic liver diseases Hum Cell 1999; 12: 171-180.

2. Gupta S, Aragona E, Vemuru RP, Bhargava KK, Burk RD, Chowdhury JR. Permanent engraftment and function of hepatocytes delivered to the liver: implications for gene therapy and liver repopulation. Hepatology 1991; 14: 144-149.

3. Fox IJ, Chowdhury JR, Kaufman SS, Goertzen TC, Chowdhury NR, Warkentin PI et al. Treatment of the Crigler-Naijar syndrome type I with hepatocyte transplantation. N Engl J Med 1998; 338: 1422-1426.

4. Grompe M, Laconi E, Shafritz DA. Principles of therapeutic liver repopulation. Semin Live Dis 1999; 19: 7-14.

5. Laconi S, Pillai S, Porcu PP, Shafritz DA, Pani P, Laconi E. Massive liver replacement by transplanted hepatocytes in the absence of exogenous growth stimuli in rats treated with retrorsine. Am J Pathol 2001; 158: 771-777.

6. Rhim JA, Sandgren EP, Degen JL, Palmiter RD, Brinster RL. Replacement of diseased mouse liver by hepatic cell transplantation. Science 1994; 263: 1149-1152.

7. Karnezis AN, Dorokhov M, Grompe M, Zhu L. Loss of p27 (Kip1) enhances the transplantation efficiency of hepatocytes transferred into diseased livers. J Clin Invest 2001; 108: 383-390.

8. Chen WD, Wang YD, Zhang L, Shiah S, Wang M, Yang F et al. Farnesoid X receptor alleviates age-related proliferation defects in regenerating mouse livers by activating forkhead box m1b transcription. Hepatology 2010; 51: 953-962.

9. Wang IC, Chen YJ, Hughes D, Petrovic V, Major ML, Park HJ et al. Forkhead box M1 regulates the transcriptional network of genes essential for mitotic progression and genes encoding the SCF (Skp2-Cks1) ubiquitin ligase. Mol Cell Biol 2005; 25: 10875-10894.

10. Krupczak-Hollis K, Wang X, Kalinichenko VV, Gusarova GA, Wang IC, Dennewitz MB et al. The mouse Forkhead Box $\mathrm{m} 1$ transcription factor is essential for hepatoblast mitosis and development of intrahepatic bile ducts and vessels during liver morphogenesis. Dev Biol 2004; 276: 74-88

11. Ye H, Holterman AX, Yoo KW, Franks RR, Costa RH. Premature expression of the winged helix transcription factor $\mathrm{HFH}-11 \mathrm{~B}$ in regenerating mouse liver accelerates hepatocyte entry into S phase. Mol Cell Biol 1999; 19: 8570-8580.

12. Wang X, Kiyokawa H, Dennewitz MB, Costa RH. The Forkhead Box m1b transcription factor is essential for hepatocyte DNA replication and mitosis during mouse liver regeneration. Proc Natl Acad Sci USA 2002; 99: 16881-16886.

13. Krupczak-Hollis $\mathrm{K}$, Wang $\mathrm{X}$, Dennewitz MB, Costa RH. Growth hormone stimulates proliferation of old-aged regenerating liver through forkhead box m1b. Hepatology 2003 ; 38: $1552-1562$

14. Wang X, Krupczak-Hollis K, Tan Y, Dennewitz MB, Adami GR, Costa RH. Increased hepatic Forkhead Box M1B (FoxM1B) levels in old-aged mice stimulated liver regeneration through diminished p27Kip1 protein levels and increased Cdc25B expression. J Biol Chem 2002; 277: 44310-44316.

15. Brezillon N, Lambert-Blot M, Morosan S, Couton D, Mitchell C, Kremsdorf D et al. Transplanted hepatocytes over-expressing FoxM1B efficiently repopulate chronically injured mouse liver independent of donor age. Mol Ther 2007; 15: 1710-1715.

16. Huang L, Hung MC, Wagner E (eds) Nonviral Vectors for Gene Therapy. Elsevier Academic Press: San Diego, CA, USA, Vol 54, 2005, pp 189-232.

17. Kebriaei $P$, Huls $H$, Jena B, Munsell M, Jackson R, Lee DA et al. Infusing CD19-directed T cells to augment disease control in patients undergoing autologous hematopoietic stem-cell transplantation for advanced B-lymphoid malignancies. Hum Gene Ther 2012; 23: $444-450$

18. Overturf K, Al-Dhalimy M, Tanguay R, Brantly M, Ou CN, Finegold M et al. Hepatocytes corrected by gene therapy are selected in vivo in a murine model of hereditary tyrosinaemia type I. Nat Genet 1996; 12: 266-273.

19. He Z, Zhang H, Zhang X, Xie D, Chen Y, Wangensteen KJ et al. Liver xeno-repopulation with human hepatocytes in Fah $-/$ - Rag2 $-/$ - mice after pharmacological immunosuppression. Am J Pathol 2010; 177: 1311-1319.
20. Wang X, Foster M, Al-Dhalimy M, Lagasse E, Finegold M, Grompe M. The origin and liver repopulating capacity of murine oval cells. Proc Natl Acad Sci USA 2003; 100(Suppl 1): 11881-11888

21. Wilber A, Wangensteen KJ, Chen Y, Zhuo L, Frandsen JL, Bell JB et al. Messenger RNA as a source of transposase for sleeping beauty transposon-mediated correction of hereditary tyrosinemia type I. Mol Ther 2007; 15: 1280-1287.

22. Wangensteen KJ, Wilber A, Keng VW, He Z, Matise I, Wangensteen $L$ et al. A facile method for somatic, lifelong manipulation of multiple genes in the mouse liver. Hepatology 2008; 47: 1714-1724.

23. Overturf K, al-Dhalimy M, Ou CN, Finegold M, Grompe M. Serial transplantation reveals the stem-cell-like regenerative potential of adult mouse hepatocytes. Am J Pathol 1997; 151: 1273-1280.

24. Grompe M, Lindstedt S, al-Dhalimy M, Kennaway NG, Papaconstantinou J, Torres-Ramos $\mathrm{CA}$ et al. Pharmacological correction of neonatal lethal hepatic dysfunction in a murine model of hereditary tyrosinaemia type I. Nat Genet 1995; 10: 453-460.

25. Leung TW, Lin SS, Tsang AC, Tong CS, Ching JC, Leung WY et al. Over-expression of FoxM1 stimulates cyclin B1 expression. FEBS Lett 2001; 507: 59-66.

26. Duncan AW, Taylor MH, Hickey RD, Hanlon Newell AE, Lenzi ML, Olson SB et al. The ploidy-conveyor of mature hepatocytes as a source of genetic variation. Nature 2010; 467: 707-710.

27. Huang $\mathrm{P}, \mathrm{He} \mathrm{Z}$, Ji S, Sun $\mathrm{H}$, Xiang D, Liu C et al. Induction of functional hepatocyte-like cells from mouse fibroblasts by defined factors. Nature 2011; 475: 386-389.

28. Neo SY, Leow CK, Vega VB, Long PM, Islam AF, Lai PB et al. Identification of discriminators of hepatoma by gene expression profiling using a minimal dataset approach. Hepatology 2004; 39: 944-953.

29. Hsieh SY, He JR, Hsu CY, Chen WJ, Bera R, Lin KY. Neuregulin/erythroblastic leukemia viral oncogene homolog 3 autocrine loop contributes to invasion and early recurrence of human hepatoma. Hepatology 2011; 53: 504-516.

30. Kay MA, High K. Gene therapy for the hemophilias. Proc Natl Acad Sci USA 1999; 96: 9973-9975.

31. Yamanouchi K, Zhou H, Roy-Chowdhury N, Macaluso F, Liu L, Yamamoto T et al. Hepatic irradiation augments engraftment of donor cells following hepatocyte transplantation. Hepatology 2009; 49: 258-267.

32. Paulk NK, Wursthorn K, Haft A, Pelz C, Clarke G, Newell AH et al. In vivo selection of transplanted hepatocytes by pharmacological inhibition of fumarylacetoacetate hydrolase in wild-type mice. Mol Ther 2012; 20: 1981-1987.

33. Kalinina OA, Kalinin SA, Polack EW, Mikaelian I, Panda S, Costa RH et al. Sustained hepatic expression of FoxM1B in transgenic mice has minimal effects on hepatocellular carcinoma development but increases cell proliferation rates in preneoplastic and early neoplastic lesions. Oncogene 2003; 22: 6266-6276.

34. Bell JB, Aronovich EL, Schreifels JM, Beadnell TC, Hackett PB. Duration of expression and activity of Sleeping Beauty transposase in mouse liver following hydrodynamic DNA delivery. Mol Ther 2010; 18: 1796-1802.

35. Zayed H, Izsvák Z, Walisko O, Ivics Z. Development of hyperactive sleeping beauty transposon vectors by mutational analysis. Mol Ther 2004; 9: 292-304.

36. Yant SR, Meuse L, Chiu W, Ivics Z, Izsvak Z, Kay MA. Somatic integration and long-term transgene expression in normal and haemophilic mice using a DNA transposon system. Nat Genet 2000; 25: 35-41.

37. Li F, Liu P, Liu C, Xiang D, Deng L, Li W et al. Hepatoblast-like progenitor cells derived from embryonic stem cells can repopulate livers of mice. Gastroenterology 2010; 139: 2158-2169; e8.

38. He ZY, Deng L, Li YF, Xiang D, Hu JK, Chen YX et al. Murine embryonic stem cell-derived hepatocytes correct metabolic liver disease after serial liver repopulation. Int J Biochem Cell Biol 2012; 44: 648-658.

39. Yu B, He ZY, You P, Han QW, Xiang D, Chen F et al. Reprogramming fibroblasts into bipotential hepatic stem cells by defined factors. Cell Stem Cell 2013; 13: 328-340.

40. Mitchell $C$, Willenbring $H$. A reproducible and well-tolerated method for $2 / 3$ partial hepatectomy in mice. Nat Protoc 2008; 3: 1167-1170.

41. Guidotti JE, Bregerie O, Robert A, Debey P, Brechot C, Desdouets C. Liver cell polyploidization: a pivotal role for binuclear hepatocytes. J Biol Chem 2003; 278 : 19095-19101.

(c) (i) () $\ominus$ Cell Death and Disease is an open-access journal published by Nature Publishing Group. This work is licensed under a Creative Commons Attribution-NonCommercialNoDerivs 3.0 Unported License. The images or other third party material in this article are included in the article's Creative Commons license, unless indicated otherwise in the credit line; if the material is not included under the Creative Commons license, users will need to obtain permission from the license holder to reproduce the material. To view a copy of this license, visit http://creativecommons.org/ licenses/by-nc-nd/3.0/ 